\title{
Prevalence and patterns of coronary artery disease in patients undergoing cardiac surgery for rheumatic and non- rheumatic valvular heart disease in a tertiary care center of Nepal.
}

\author{
Ravi Sahi, Arun Sayami, Ratna Mani Gajurel, Chandra Mani Poudel, Hemant Shrestha, Sanjeev Thapa, \\ Rajaram Khanal, Surya Devkota, Abhishesh Shakya, Sheelendra Shakya
}

Department of Cardiology, Manmohan Cardio Vascular Thoracic and Transplant Centre (MCVTC), Institute of Medicine, TUTH, Nepal

Corresponding Author: Ravi Sahi

Department of Cardiology, Manmohan Cardio Vascular Thoracic and Transplant Centre (MCVTC), Institute of Medicine, TUTH, Nepal Email: drravisahi@gmail.com

Phone no: +9779841759273

\begin{abstract}
Cite this article as: Sahi R, Sayami A, Gajurel RM, et.al. Prevalence and patterns of coronary artery disease in patients undergoing cardiac surgery for rheumatic and non- rheumatic valvular heart disease in a tertiary care center of Nepal. Nepalese Heart Journal 2018; 15(2): 21-24.
\end{abstract}

Received date: 19 th June 2018

Accepted date: 20th September 2018

\section{Abstract}

Background and Aims: Coronary artery disease (CAD) constitute a major cause of cardiovascular morbidity and mortality worldwide with an enormous burden on healthcare resources. Prevalence and pattern of CAD in patients of rheumatic and non-rhemuatic valvular heart diseases varies widely with limited data on optimal strategies for diagnosis and treatment.

Methods: This study includes 97 patients with rheumatic and non-rheumatic valvular heart disease who underwent coronary angiogram (CAG) before cardiac surgery. Patients were divided into two groups based on rheumatic heart disease (RHD) \& non-rheumatic disease (Non-RHD) and correlate the patterns of CAD.

Results: Out of 97 patients, 22 (22.6\%) patients were found to have significant CAD. In patients with non-rheumatic origin CAD was common (15 patients, $68.1 \%$ ) as compared to rheumatic origin (7 patients, $31.8 \%$ ). In rheumatic origin, the prevalence was $7(12.2 \%)$ out of 57 patients while in non-rheumatic origin, was $15(37.5 \%)$ out of 40 patients. In RHD group, all patients with CAD were found to have single vessel diease (SVD) while, in non-RHD group, 11 patients (73.3\%) had SVD, 3 patients (16.7\%) had double vessel disease (DVD) and one patient (5.6\%) had triple vessel disease (TVD).

Conclusions: Prevalence of CAD is higher in patients with non-RHD in comparison to those with RHD. We also found SVD to be the most common pattern of CAD in both rheumatic and non-rheumatic valvular heart disease.

Keywords: Bicuspid aortic valve; coronary artery disease; coronary angiography; degenerative valvular heart disease; mitral valve prolapse.

\section{Introduction}

Rheumatic heart disease (RHD) continues to be the dominant form of valvular heart disease in developing nations ${ }^{1}$. There are limited data regarding optimal strategies for diagnosis and treatment of coronary artery disease $(\mathrm{CAD})$ in patients with valvular and non valvular heart disease having concomitant $\mathrm{CAD}$. The strategies for diagnosis of CAD were followed from the smaller published series of patients who underwent surgical treatment for valvular heart disease (VHD). The pre-operative identification of CAD even in asymptomatic patients is quite significant because there is negative impact of untreated CAD both on perioperative and long term postoperative outcomes. ${ }^{2,3}$

American College of Cardiology/American Heart Association (ACC/AHA) guidelines for coronary angiography 
(CAG) has been followed to anticipate risks in patients with RHD and non-rheumatic VHD ${ }^{4}$. In clinical practice, we have noticed that prevalence rate of $\mathrm{CAD}$ with rheumatic origin is low among patients with valvulopathies. It is exceptional that although the non-rheumatic origin of the valvulopathies is often found in our population, the rheumatic origin still considerably outnumbers the first ${ }^{5,6}$. In the developed western part, CAD is more commonly associated with valvular heart disease ${ }^{7}$.

In several trials the incidence of associated CAD in acquired valvular diseases has been studied ${ }^{8-11}$. But there is limited data regarding the prevalence of $\mathrm{CAD}$ in rheumatic heart disease patients. It is suspected that intra myocardial coronary arteries may be involved in the form of an arteritis in rheumatic fever ${ }^{12}$. The clinical and autopsy findings in patients who died of myocardial infarction showed rheumatic heart disease to be quite rare $^{13}$. Due to which it is acknowledged that myocardial infarction most commonly occurs in association with atherosclerotic heart disease. So the impact of CAD is not well formed with its relation to rheumatic valvular disease. In few studies, association of RHD with coronary artery disease results in poor prognosis. ${ }^{8,10,14}$

\section{Methods:}

Here we evaluate the prevalence of coexistent coronary artery disease and its risk factors in patients who underwent valve surgery for rheumatic and non-rheumatic valvular heart disease in last one year at Manmohan Cardio Vascular Thoracic and Transplant Centre (MCVTC). Non-rheumatic valvular heart diease includes degenerative valvular heart disease (DVHD), mitral valve prolapse (MVP), bicuspid aortic valve (BAV). The transthoracic echocardiogram (TTE) have been mainly used to evaluate the origin of cardiac diseases. The trans-esophageal echocardiogram was also used when TTE was non-decisive, with two dimensional and color flow imaging. No tissue sampling was done. All patients underwent CAG with informed written consent. Angiogram report showing presence of coronary artery disease (defined as $>50 \%$ luminal stenosis) and the number of lesioned coronary arteries were collected.

\section{Inclusion Criteria:}

Rheumatic and non-rheumatic valvular heart disease patients prior to valve replacement/repair surgery in which

1. Men of $>40$ years old.

2. Postmenopausal women,

3. Patient presenting with symptoms of angina and objective evidence of ischemia.

\section{Exclusion Criteria}

1. Men of $<40$ years old.

2. Pre-menopausal women without any symptoms of angina or objective evidence of ischemia.

3. Patient who underwent CAG within last 3 months.

4. Patient with history of CAD.

\section{Statistical Analysis:}

All statistical analysis was performed using SPSS version 20.0. Categorical data were analyzed in terms of frequency and continuous data presented as means \pm SD. Dichotomous variables were compared by Chi- square test and independent samples $t$ test used to compare means of continuous variables. The $\mathrm{p}$ value $<0.05$ was considered significant.

\section{Results:}

A total of 97 patients with valvular heart diseases were included in the study. Majority of the patients (57 patients, 58.7\%) had rheumatic etiology while the second most common origin was degenerative valvular heart disease (31 patients, $31.9 \%$ ). The mean age of patients in rheumatic group was $51 \pm 7.7$ years and non-rheumatic group was $61 \pm 9.9$ years.

\begin{tabular}{lccccc}
\hline \multicolumn{5}{c}{ Table 1: Baseline Clinical Characteristics } \\
& $\begin{array}{c}\text { With CAD } \\
(\mathrm{n}=22)\end{array}$ & $\begin{array}{c}\text { Without CAD } \\
(\mathrm{n}=75)\end{array}$ & p value \\
\hline Variables & $\mathrm{n}$ & $\%$ & $\mathrm{n}$ & $\%$ & \\
\hline Age $<50$ years & 3 & 13.6 & 30 & 40 & $<0.001$ \\
\hline Age 50-60 years & 3 & 13.6 & 28 & 37.3 & \\
\hline Age $>60$ years & 16 & 72.7 & 17 & 22.6 & \\
\hline Males & 9 & 40.9 & 29 & 38.6 & 0.85 \\
\hline Females & 13 & 59 & 46 & 61.3 & \\
\hline Typical chest pain & 3 & 13.6 & 6 & 8 & 0.423 \\
\hline Atypical chest pain & 8 & 36.4 & 11 & 14.7 & 0.024 \\
\hline No chest pain & 11 & 50 & 58 & 77.3 & 0.013 \\
\hline BMI <25 & 14 & 63.6 & 66 & 88 & 0.008 \\
\hline BMI $>25$ & 8 & 36.3 & 9 & 12 & \\
\hline Diabetes & 7 & 31.8 & 3 & 4 & $<0.001$ \\
\hline Hypertension & 8 & 36.4 & 7 & 9.3 & 0.002 \\
\hline Dyslipidemia & 6 & 27.3 & 5 & 6.7 & 0.007 \\
\hline Smokers & 5 & 22.7 & 2 & 2.7 & 0.001 \\
\hline Family history of & 1 & 4.5 & 2 & 2.7 & 0.654 \\
CAD & & & & & \\
\hline RHD & 7 & 31.8 & 50 & 66.7 & 0.003 \\
\hline MVP & 1 & 4.5 & 2 & 2.7 & 0.654 \\
\hline DVHD & 2 & 54.5 & 19 & 25.3 & 0.009 \\
\hline BAV & & & 4 & 5.3 & 0.52 \\
\hline
\end{tabular}

Table 2: Prevalence and severity of CAD in relation to different etiologies (Rheumatic vs Non-rheumatic etiology group)

\begin{tabular}{|c|c|c|c|c|c|}
\hline Lesion & $\begin{array}{c}\text { CAD } \\
\text { patients }\end{array}$ & $\begin{array}{l}\text { SVD } \\
(\%)\end{array}$ & $\begin{array}{c}\text { DVD } \\
(\%)\end{array}$ & $\begin{array}{l}\text { TVD } \\
(\%)\end{array}$ & $\begin{array}{c}\text { LMD } \\
(\%)\end{array}$ \\
\hline $\begin{array}{l}\text { Valvular } \\
(\mathrm{n}=97)\end{array}$ & $\mathrm{n}=22$ & $\mathrm{n}=18$ & $\mathrm{n}=3$ & $\mathrm{n}=1$ & $\mathrm{n}=0$ \\
\hline RHD & $\begin{array}{c}7 \\
(12.2 \%)\end{array}$ & $\begin{array}{c}7 \\
(12.2 \%)\end{array}$ & 0 & 0 & 0 \\
\hline \multicolumn{6}{|c|}{ Non-RHD } \\
\hline DVHD & $\begin{array}{c}12 \\
(38.7 \%)\end{array}$ & $\begin{array}{c}9 \\
(29 \%)\end{array}$ & $\begin{array}{c}2 \\
(6.5 \%)\end{array}$ & $\begin{array}{c}1 \\
(3.2 \%)\end{array}$ & 0 \\
\hline MVP & $\begin{array}{c}1 \\
(33.3 \%)\end{array}$ & 0 & $\begin{array}{c}1 \\
(33.3 \%)\end{array}$ & 0 & 0 \\
\hline BAV & $\begin{array}{c}2 \\
(33.3 \%)\end{array}$ & $\begin{array}{c}2 \\
(33.3 \%)\end{array}$ & 0 & 0 & 0 \\
\hline
\end{tabular}

$C A D$, coronary artery disease; RHD, rheumatic heart disease; MVP, mitral valve prolapse; $B A V$, bicuspid aortic valve, DVHD, Degenerative Valvular Heart Disease); SVD, single vessel disease; DVD, double vessel disease; TVD, triple vessel disease; $L M D$, left main disease.

Baseline characteristics of different groups are shown in table 1. Out of 97 patients, $22(22.6 \%)$ patients had significant CAD, which was more common in DVHD patients $(12,54.5 \%)$ in comparision to rheumatic, BAV and MVP (7(31.8\%), 2(9.1\%), $1(4.5 \%)$ respectively. The $8 \%$ of patients without CAD had typical chest pain, which was due to Aortic stenosis. 
In non-rheumatic group as mentioned in table 2, the prevalence of $\mathrm{CAD}$ was higher, 15 patients (68.1\%), as compared to rheumatic group. CAD was most prevalent in DVHD patients (12 patients, 38.7\%). Among, 12 patients of DVHD and CAD, nine had single vessel disease (SVD) (29\%), two had double vessel disease (DVD) $(6.5 \%)$ and only one patient had triple vessel disease (TVD) (3.2\%).Out of three patients with MVP only one had CAD which was DVD (33.3\%) while six patients in BAV only two had CAD both of whom had SVD (33\%).

Among 22 patients with CAD, only seven patients (31.8\%) were with RHD and all of them had SVD. Thus the prevalence of CAD in rheumatic (57 patients) compared to non-rheumatic VHD (40 patients) of our study was $12.2 \%$ \& $37.5 \%$ respectively.

\section{Discussion}

In patients with valvular heart diseases, the higher number of patients had degenerative origin ${ }^{15}$. The overall prevalence of CAD has been shown to vary widely from $9 \%$ to $41 \%$ in patients undergoing valve replacement surgery $8,10,14,16-18$.

Elderly patients had degenerative valve disease and multiple coronary risk factors. The most common origin of VHD is rheumatic in developing countries. And, the prevalence of coexistent CAD is very low in comparision to patients with western countries ${ }^{19-21}$. In our study the prevalence of coronary artery disease in all groups was $22.6 \%$, which is very low as compare with western world.

In the study of Cholenahally Nanjappa Manjunath et $\mathrm{al}^{22}$ the overall prevalence of coronary artery disease was $8.7 \%$, and the prevalence in RHD was $4.9 \%$, which is much lower when compared with our study.

Marchant et $\mathrm{al}^{23}$ assessed coronary angiogram of 100 rheumatic valvular disease patients. According to them, the prevalence of coronary artery disease was $14 \%$, which is quite similar to our study.

Shaikh et $\mathrm{al}^{24}$ reviewed medical data of 144 RHD patients, $25 \%$ of whom had CAD, which might be related to the higher frequency of DM, HTN and dyslipidemia in these patients. Similar to our study, Jose et $\mathrm{al}^{19}$ and Narang et $\mathrm{al}^{25}$ showed that the prevalence rate of CAD in RHD patients undergoing cardiac surgery was $12.2 \%$ and $11 \%$ respectively.

Kruczan et $\mathrm{al},{ }^{21}$ evaluated 294 patients with rheumatic and non-rheumatic VHD and stated that the patients with non rheumatic VHD had higher prevalence of CAD (33.61\%) when compared to those with rheumatic VHD (4\%). Xu et.al. reported the prevalence of CAD in DVHD to be $9.57 \%$ among 491 patients which is much lower than our study (38.7\%). The prevalence of $\mathrm{CAD}$ was found to be lower in rheumatic origin as many patients in our study were from a lower economic and sociological position.

In the study of Choudhary et.al ${ }^{27}$ among patients of RHD with CAD, 64(58.7\%) patients had SVD, 30(27.5\%) had DVD and $15(13.8 \%)$ had TVD while in non RHD with CAD 32 (29.4\%) had SVD, 39(35.8\%) had DVD and 38(34.9\%) had TVD. In our study the most common pattern of CAD was SVD in both groups. In RHD group, all patients with CAD were found to have SVD while, in non-RHD group, only 11 patients $(73.3 \%)$ had SVD. Among remaining four patients, three patients (16.7\%) had DVD and one patient (5.6\%) had TVD.

\section{Limitation of the study:}

This is a single center study with small sample size especially of non-rheumatic valvular heart disease like MVP and BAV.

\section{Conclusion:}

We conclude that the prevalence of $\mathrm{CAD}$ is higher in Nepalese patients with non-RHD in comparison to those with RHD. We also found SVD to be the most common pattern of CAD in both rheumatic and non-rheumatic valvular heart disease.

Table 2: Prevalence and severity of CAD in relation to different etiologies (Rheumatic vs Non-rheumatic etiology group)

\begin{tabular}{lccccc} 
Lesion & $\begin{array}{c}\text { CAD } \\
\text { patients }\end{array}$ & $\begin{array}{c}\text { SVD } \\
(\%)\end{array}$ & $\begin{array}{c}\text { DVD } \\
(\%)\end{array}$ & $\begin{array}{c}\text { TVD } \\
(\%)\end{array}$ & $\begin{array}{c}\text { LMD } \\
(\%)\end{array}$ \\
$\begin{array}{l}\text { Valvular } \\
(\mathrm{n}=97)\end{array}$ & $\mathrm{n}=22$ & $\mathrm{n}=18$ & $\mathrm{n}=3$ & $\mathrm{n}=1$ & $\mathrm{n}=0$ \\
RHD & $\begin{array}{c}7 \\
(12.2 \%)\end{array}$ & $\begin{array}{c}7 \\
(12.2 \%)\end{array}$ & 0 & 0 & 0 \\
\hline
\end{tabular}

\begin{tabular}{lccccc|} 
Non-RHD & \multicolumn{1}{c}{} & & & & \\
DVHD & 12 & 9 & 2 & 1 & 0 \\
MVP & $(38.7 \%)$ & $(29 \%)$ & $(6.5 \%)$ & $(3.2 \%)$ & \\
& 1 & 0 & 1 & 0 & 0 \\
BAV & $(33.3 \%)$ & & $(33.3 \%)$ & & \\
& $(33.3 \%)$ & $(33.3 \%)$ & & 0 & 0 \\
\hline
\end{tabular}

\section{Conflict of interest}

The authors do not have any conflict of interest including financial in publication of this article.

\section{References:}

1. Carapetis JR. Rheumatic heart disease in developing countries. N Engl J Med. 2007;357:439e441.

2. Czer LS, Gray RJ, DeRobertis MA, et al. Mitral valve replacement: impact of coronary artery disease and determinants of prognosis after revascularization. Circulation. 1984;70:I198eI207.

3. Kay PH, Nunley DL, Grunkemeier GL, Pinson CW, Starr A. Late results of combined mitral valve replacement and coronary bypass surgery. J Am Coll Cardiol. 1985;5:29e33.

4. Nishimura RA, Otto CM, Bonow RO, et al. 2014 AHA/ ACC guideline for the management of patients with valvular heart disease: executive summary: a report of the American College of Cardiology/American Heart Association Task Force on Practice Guidelines. Circulation. 2014;129:2440 2492. https://doi.org/10.1161/CIR.0000000000000029

5. Argüelles E, Fiszman P, Fakoury L. Febre reumática edoenças valvulares do coração. Rio de Janeiro: Intermédica, 1984.

6. Terreri MT, Len C, Hilário MOE, Goldenberg MB. Utilização de recursos e custos de pacientes com febre reumática. Rev Bras Reumatol. 2002; 42 (4): 211-7.

7. Bozbaş H, Yildirir A, Küçük MA et.al. Prevalence of coronary artery disease in patients undergoing valvular operation due to rheumatic involvement. Anadolu Kardiyol Derg. 2004;4:223-226.

8. Befeler B, Kamen AR, Macleod MB. Coronary artery disease and left ventricular function in mitral stenosis. Chest 1970; 57: 435-9. 7.

9. Bonchek LI, Anderson RP, Rösch J. Should coronary arteriography be performed routinely before valve replacement? Am J Cardiol 1973; 31: 462-6. https://doi.org/10.1016/0002-9149(73)90295-6

10. Baxter RH, Reid JM, McGuiness JB, Stevenson JG. Relation of angina to coronary artery disease in mitral and aortic valve disease. Br Heart J 1978; 40: 918-22. 9.

11. Gomez Doblas J, Jimenez Navarro M, Rodriguez Bailon I, et al. Preoperative coronarography in heart valve disease patients. A probability analysis of coronary lesion. Rev Esp 
Cardiol 1998; 51: 756-61.

12. Essop MR, Skudicky D, Tanvier O, Sareli P. Rheumatic fever. In: Crawford MH, DiMarco JP, editors. Cardiology. London: Mosby International Limited; 2001: p.6.3.1-8. 11.

13. Khetagurov AD, Saksonov SI. Myocardial infarct in rheumatic mitral valve defects. Ter Arkh 1985; 57: 108-10.

14. Coleman EH, Soloff LA. Incidence of significant coronary artery disease in rheumatic valvular heart disease. Am J Cardiol 1970;25:401 4.

https://doi.org/10.1016/0002-9149(70)90004-4

15. Bonow RO, Carabello BA, Chatterjee K, et.al. 2008 focused update incorporated into the ACC/AHA 2006 guidelines for the management of patients with valvular heart disease: a report of the American College of Cardiology/American Heart Association Task Force on Practice Guidelines (Writing Committee to revise the 1998 guidelines for the management of patients with valvular heart disease). Endorsed by the Society of Cardiovascular Anesthesiologists, Society for Cardiovascular Angiography and Interventions, and Society of Thoracic Surgeons. J Am Coll Cardiol. 2008;23:e1ee142.

16. Sonmez K, Gencbay M, Akcay A, et al. Prevalence and predictors of significant coronary artery disease in Turkish patients who undergo heart valve surgery. J Heart Valve Dis. 2002;11:431e437.

17. Schaefer A, Jehle J, Loogen F. Indications for coronary angiography in patients with acquired heart valve diseases with reference to risk factors. Z Kardiol. 1987;76:276e283.

18. Lacy J, Goodin R, McMartin D, Masden R, Flowers N. Coronary atherosclerosis in valvular heart disease. Ann Thorac Surg. 1977;23:429e435.

19. Jose VJ, Gupta SN, Joseph G, et al. Prevalence of coronary artery disease in patients with rheum-atic heart disease in the current era. Indian Heart J. 2004;56:129e131.

20. Guray Y, Guray U, Yilmaz MB, Mecit B, Kisacik H,
Korkmaz S. Prevalence of angiographically significant coronary artery disease in patients with rheumatic mitral stenosis. Acta Cardiol. 2004;59:305e309.

21. Kruczan DD, Silva NA, Pereira Bde B et.al. Coronary artery disease in patients with rheumatic and non-rheumatic valvular heart disease treated at a public hospital in Rio de Janeiro. Arq Bras Cardiol. 2008;90:197e203.

22. Manjunath $\mathrm{CN}$, Agarwal $\mathrm{A}$, Bhat $\mathrm{P}$ et al Coronary artery disease in patients undergoing cardiac surgery for non-coronary lesions in a tertiary care centre. Indian heart journal 2014;66:52e56. https://doi.org/10.1016/j.ihj.2013.12.014

23. Marchant E, Pichard A, Casanegra P. Association of coronary artery disease and valvular heart disease in Chile. Clin Cardiol. 1983;6:352e356.

24. Shaikh Ayaz Hussain, Hanif Bashir, Hasan Khursheed, et al. Coronary artery disease in patients undergoing valve replacement at a tertiary care cardiac centre. JPMA. 2011;61:340

25. Narang R, Chadha DS, Goel K, et al. Screening coronary angiography prior to surgery in rheumatic valvular heart disease: a study of 2,188 patients. J Heart Valve Dis. 2009; $18: 455$ e 462 .

26. Xu ZJ, Pan J, Zhou Q et al. Analysis of the prevalence and risk factors of pre operative angiography confirmed coronary artery stenosis in patients with degenerative valvular heart disease. Zhonghua Xin Xue Guan Bing Za Zhi. 2017;45:837-842.https//doi.org/10.3760/cma.j.is sn.0253-3758.2017.10.005

27. Choudhary D, Chaurasia AK, Rohan V Aet al. Prevalence of Coronary Artery Disease in Rheumatic Heart Disease and Comparison of Demographic and Coronary Artery Disease Profile with Atherosclerotic Coronary Artery Disease. Adv Hum Biol 2016;6:76-83

https://doi.org/10.4103/2321-8568.190322 